\title{
GRUPO TERAPÊUTICO COM ESTUDANTES EM MODO VIRTUAL: RELATO DE EXPERIÊNCIA EM PSICOLOGIA
}

\author{
Natalia da Silva Fontinelli'; ${ }^{1}$ Maria Eduarda Silva da Silva²; Marina Peripolli \\ Antoniazzi $^{3}$
}

\section{RESUMO}

O presente estudo refere-se a um relato de experiência de estágio em psicologia, o qual teve por objetivo a proposta de uma intervenção grupal com efeitos terapêuticos. Devido ao cenário da pandemia de Coronavírus, o ambiente virtual foi a ferramenta que possibilitou a realização de um trabalho terapêutico com pré-adolescentes de uma escola da cidade de Santa Maria (RS). Vários desafios estavam envolvidos no processo, pois além das peculiaridades e novidades advindas do sistema remoto, os processos grupais e a faixa etária dos jovens também já apresentavam suas particularidades desafiadoras para se pensar um trabalho potente. No entanto, destaca-se que esse conjunto de fatores que suscitaram, por vezes, algumas reinvenções, também puderam ser trabalhados e superados, dada a disponibilidade e vontade dos integrantes do grupo, verificando-se, de fato, um caráter terapêutico gerado pelo processo.

Palavras-chave: Encontro, escola, participantes, sistema remoto.

Eixo Temático: Educação, Cultura e Comunicação (ECC)

\section{INTRODUÇÃO}

Em um contexto adverso, suscitado por uma pandemia, o ensino necessitou de rápidas reinvenções para se adaptar a novas exigências. Essa assustadora transformação, imposta por um vírus desconhecido, deu voz a diversas inseguranças, medos e angústias, os quais repercutiram na vida escolar. Demandas que já eram desafiadoras em um contexto comum de aprendizagem presencial tornaram-se

\footnotetext{
${ }^{1}$ Estudante do Curso de Psicologia da Universidade Franciscana. E-mail: natalia.fontinelli@ufn.edu.br ${ }^{2}$ Estudante do Curso de Psicologia da Universidade Franciscana. E-mail: maria.esilva@ufn.edu.br ${ }^{3}$ Professora do Curso de Psicologia da Universidade Franciscana. E-mail: m.antoniazzi@prof.ufn.edu.br
} 
maiores quando pessoas foram colocadas, de surpresa, em um ensino remoto, até então desconhecido por muitos.

A partir de tal situação, pôde-se pensar na psicologia enquanto ferramenta de inserção no cenário escolar atual e, especificamente, na modalidade de grupos terapêuticos online como uma possibilidade de auxílio no enfrentamento de problemas presentes. Nesse contexto de intervenção grupal via internet, ocorreu uma prática com pré-adolescentes para abordar sobre a experiência do ensino remoto em si, além de como esses alunos sentiam-se perante o isolamento consequente da pandemia, como se estabeleciam as relações com os familiares, entre outros assuntos surgidos, naturalmente, no decorrer do processo. A partir de demandas trazidas pelos próprios participantes do grupo, questões como jogos, bullying, ansiedade e reconhecimento das emoções também foram discutidos. Evidenciou-se, com a conclusão da intervenção, que é possível sentir-se parte de um grupo, ainda que separados por uma tela.

Destaca-se que alguns obstáculos apareceram durante o processo de intervenção grupal em modelo virtual: a dificuldade na entrega e adesão dos participantes aos encontros grupais ocorreram nas primeiras tentativas, além de instabilidades da rede de internet e a presença de familiares, por vezes, próxima do local no qual os integrantes estavam durante os encontros grupais online, causando algumas interferências na comunicação (ainda que tivessem sido recomendados a permanecerem em um ambiente isolado, se possível). No entanto, dados os benefícios que uma intervenção grupal em psicologia pode fornecer, mesmo diante dos desafios, salienta-se os resultados satisfatórios advindos do vínculo que se criou entre os alunos e as coordenadoras do grupo ao longo do processo. Guiando-se com o objetivo da proposta de intervenção grupal atrelada ao cenário escolar, justifica-se a escolha dessa prática para atuação da psicologia, na presente experiência, porque o trabalho com grupos proporciona um caráter vivencial e relacional das questões trabalhadas, podendo potencializar alguns efeitos terapêuticos aos jovens envolvidos.

\section{METODOLOGIA}


A referida experiência deu-se por meio de intervenções terapêuticas grupais, realizadas em modelo remoto (assim suscitado devido ao cenário da pandemia causada pelo Coronavírus), com estudantes pré-adolescentes de uma escola da cidade de Santa Maria (RS). Juntamente com a prática, ocorreram pesquisas de caráter qualitativo a respeito de fenômenos grupais em psicologia, bem como sobre o cenário escolar e a faixa etária dos integrantes do processo grupal em questão, além de pesquisas sobre a particularidade das intervenções no formato remoto.

Os encontros ocorreram entre os meses de maio e junho de 2021 , todas as terças-feiras, às 11h, com duração de uma hora (com exceção de alguns que se prolongaram), contabilizando oito encontros no total. Realizou-se um contrato verbal com os participantes do grupo, no qual questões referentes ao andamento dos encontros e combinações necessárias foram debatidas. Novos participantes chegaram após a intervenção já ter iniciado, e a cada vez o contrato era retomado. Em geral, os encontros contaram com uma média de quatro participantes, sendo que ao final do processo eram os mais assíduos que continuaram a frequentar. Durante a semana acontecia a produção dos materiais que seriam utilizados nos próximos encontros com os jovens. Houve também a construção de relatórios semanais que eram, posteriormente, discutidos em supervisão. Ademais, a referida prática foi um dos estágios obrigatórios do curso de psicologia da Universidade Franciscana.

\section{RESULTADOS E DISCUSSÕES}

\subsection{Internvenção Grupal \& Ambiente Virtual \& Contexto Escolar}

Grupos constituem-se em um fenômeno que ocorre naturalmente na sociedade. No entanto, para que um grupo passe a ter um efeito terapêutico aos sujeitos, alguns desafios podem surgir, podendo a psicologia ser uma ferramenta em alguns casos. Sueli discorre sobre Martín-Baró e ressalta que um grupo não pode ser reduzido à soma de seus membros, além de alertar que o vínculo entre os indivíduos e a interdependência advinda de tal vínculo auxiliam a estruturar os indivíduos enquanto membros (MARTINS, 2003). Nessa perspectiva, infere-se das ideias da autora que, na medida em que os participantes de um grupo de uma intervenção em psicologia se vincularem através das dinâmicas e processos que ocorram, o laço entre 
o grupo pode também se tornar mais intenso e, possivelmente, seu caráter terapêutico aumente para os participantes.

De acordo com Donnamaria \& Terzis (2011), há a hipótese de que, nos grupos via internet, a fala possa agregar elementos que, presencialmente, ficariam apenas na comunicação não verbal. Logo, de acordo com as ideias dos autores, entende-se que esse fenômeno expõe uma particularidade positiva do grupo online, no qual os integrantes às vezes se esforçam por se fazerem compreendidos, dependendo da circunstância. Todavia, implicitamente, também remonta ao fato de que os coordenadores do grupo devem estar mais atentos para quando estiverem acontecendo situações da comunicação não verbal que não aparecem na tela.

$\mathrm{Na}$ sequência das ideias apresentadas, ao incluir o contexto escolar nessa tentativa de formação de grupos online, pode-se também trazer Weiss (2020), para a qual há o conceito de "fracasso escolar". Nele, a autora salienta que as dificuldades de aprendizagem do próprio aluno são uma das causas do fracasso escolar, mas que essa questão abrange diversos outros fatores. Assim, para a autora, o estudante que fracassa na escola pode estar refletindo alguns aspectos como os sociais e emocionais, mas até mesmo os pedagógicos, que seriam aqueles mais relacionados à maneira com a qual a escola prossegue com o ensino. Monteiro (2020), referindose à pandemia, relembra que toda experiência só pode ser avaliada quando já é passado, mas que nossas estratégias do presente podem reverberar no futuro. Desse modo, de acordo com a autora, pode-se relacionar que ainda estão se dando, no presente, as dificuldades de ensino e aprendizagem relativas à covid-19, e que a dimensão das mesmas poderão ser melhor avaliadas quando esse cenário for superado. No entanto, dada a complexidade da situação, prezando-se por atitudes preventivas de danos futuros - como de fracasso escolar atrelado às mudanças decorrentes do contexto atual e adaptações urgentes ao ambiente virtual - a intervenção grupal ocorre, sendo descrita a seguir.

\subsection{Os Encontros}

\subsubsection{Primeiro encontro - Apresentações e Combinações}


Dois participantes apareceram para o encontro (após terem sido convidados pelas coordenadoras do grupo em um espaço cedido pela escola, em uma de suas aulas virtuais) e interagiram através do bate-papo e sem câmeras ligadas, seguindo o momento da forma como foi possível diante da disponibilidade de todos. As coordenadoras propuseram uma apresentação espontânea, na qual pudessem conhecer os alunos um pouco melhor e algumas de suas preferências e interesses. Os integrantes foram convidados a ligar câmera e microfone, mas comentaram que sentiam vergonha, então foi proposto que pudessem ligá-los quando se sentissem à vontade.

Na sequência, algumas combinações foram realizadas, como as propostas por Afonso (2010), em relação ao enquadre, o qual deve ser pensado em termos de facilitar a expressão livre dos participantes, a troca de experiências, a relação com o coordenador, a privacidade dos encontros e o espaço e tempo para levar uma reflexão sobre o tema. Seguindo, conforme o andamento do grupo, alguns interesses dos participantes puderam ser conhecidos, como a identificação com jogos. Quanto ao fechamento do dia, este ocorreu com as combinações de data e horários dos próximos encontros e o questionamento aos alunos se não teria ficado nenhuma dúvida. As coordenadoras perceberam, ainda, que seria imprescindível a disposição para algumas mudanças ao longo do percurso dos encontros, e que estarem muito enrijecidas no planejamento prévio poderia ser prejudicial.

\subsubsection{Segundo encontro - Novos participantes e a retomada das apresentações}

Passaram-se duas semanas desde o primeiro encontro, uma vez que não houve adesão dos participantes na semana seguinte. Diante desse obstáculo, para tentar recuperar a participação e ampliar ainda mais a proposta do grupo, as coordenadoras expandiram o convite para mais estudantes da escola, além de procurarem saber se estava tudo bem com os que faltaram previamente, e se realmente tinham o desejo de fazer parte do grupo, então um segundo encontro ocorreu na semana seguinte.

Considerando que pessoas novas chegaram ao grupo e que havia passado bastante tempo desde o primeiro encontro, as apresentações e combinações iniciais necessitaram ser repetidas, e o andamento do dia sucedeu-se tendo essas questões 
como centrais, além de os participantes terem falado sobre suas preferências e passatempos. Conforme exposto por Neufeld, Ferreira \& Maltoni (2016), diversas vezes é preciso que regras do grupo sejam retomadas, também como uma forma de os jovens integrantes relembrarem que têm funções a desempenhar. Nesse sentido, vinculado às ideias dos autores, mostrou-se a relevância de as questões do contrato terem sido retomadas. Além disso, perguntou-se o que eles gostavam de fazer, músicas e filmes preferidos e, a partir de algumas perguntas predeterminadas, surgiram outros questionamentos e contribuições feitas livremente pelos participantes. Evidenciou-se que os integrantes começaram a conversar entre eles pelo bate-papo sobre assuntos diversos (mas dentro da temática das preferências), o que é interessante pelo ponto de vista da integração dos componentes do grupo, que por vezes pode se dar de forma gradual. Para um grupo, o processo de construção de vínculo é um ponto essencial para que os encontros grupais continuem ocorrendo de maneira satisfatória, essa inclusão e interação iniciais de um grupo pode gerar o que Berstein (1986) alude ao que Pichon-Rivière caracterizou como sentimento de pertencença, fazendo com que os membros sintam-se parte de um "nós".

\subsubsection{Terceiro encontro - Nossos Ídolos: quem são e o que representam?}

Novos participantes chegaram ainda a esse encontro, e as apresentações foram retomadas, brevemente, para que todos se conhecessem, bem como algumas combinações a respeito do funcionamento do grupo. A partir desse encontro, as interações com microfone e câmera aberta estavam ocorrendo de forma mais espontânea. Em seguida, as coordenadoras deram início a questionamentos para os participantes, tendo como temática central as referências que os jovens possuíam. Dessa forma, foram compartilhadas imagens na tela, cada uma com uma pergunta, nas quais as respostas dos participantes dessem seguimento à discussão do dia. Foi perguntado: "O que é um ídolo?”, "Você tem algum ídolo?", "Quais características que ele possui que você gostaria de ter?", "Na escola e na sua casa, quem são seus ídolos?" e "Se você pudesse ser o ídolo de alguém, como você seria?".

De acordo com Dunker (2013), a imagem que o adolescente vai construindo de si pode ser objeto de novas identificações, devendo-se considerar o grupo e as escolhas mais ou menos típicas da fase, referindo-se à imagem que vai sendo 
assumida. Nesse sentido, de acordo com as ideias do autor, um pouco do que se esperou com a dinâmica das perguntas sobre os ídolos foi que os jovens acabassem relatando seus modelos de identificação, bem como suas inspirações e, com isso, também falassem de como estão atravessando algumas questões subjetivas da préadolescência e adolescência, ainda que indiretamente. Algumas das preferências mais relatadas foram cantores de bandas de jovens, além de personagens de filmes e participantes de reality shows. Familiares e professores também foram citados.

No fechamento do encontro, foi feita uma retomada com o que foi trazido pelos integrantes, bem como o que eles conceituaram como importante a respeito de ser um ídolo e servir de inspiração para os demais. Questões como bullying apareceram, sendo que algumas das referências para eles haviam sofrido com isso. Relatos pessoais como as histórias de superação na vida dos pais também surgiram, e os próprios integrantes concluíram que tais situações são importantes e lhes inspiravam, e não apenas as pessoas famosas. Por fim, comentou-se que nossas atitudes também podem inspirar outras pessoas, e que todos podemos encontrar caminhos pessoais para desenvolver aquilo que admiramos.

\subsubsection{Quarto encontro - $O$ bullying}

A dinâmica pensada para o dia teve o bullying como tema norteador, já que no encontro passado surgiram algumas questões sobre admirar pessoas que conseguiram superar acontecimentos relacionados a essa temática. Foram compartilhadas perguntas norteadoras para o debate do dia, sendo elas: "O que é Bullying?", "Por que o Bullying acontece?", "Como se pode superar o Bullying?" O que os outros fazem e pensam de nós, é o que somos?".

A partir desses questionamentos, foram surgindo relatos - alguns falaram que sofrer bullying pode desencadear problemas sérios, como a depressão e a "vontade de se matar". Os integrantes também comentaram sobre o fato de o suporte familiar ou a sua falta fazer bastante diferença para o enfrentamento do problema. Buscou-se proceder com cautela para que houvesse o acolhimento dos jovens diante dessas questões, tentando validar suas contribuições da melhor forma possível para o momento, bem como da maneira que relatavam achar ser a certa para proceder. Além disso, a partir do que estava sendo debatido ao longo do encontro, frisou-se sobre 
formas de agir e lidar com a situação, de acordo com as ideias que foram construídas dentro do grupo.

Diversos assuntos surgiram a partir do tema central, como ansiedade, decepções, amizades, frustrações, falta de comunicação na família, sensibilidade e a importância da naturalização do choro. As coordenadoras legitimaram as questões singularidades de cada um e as construções do coletivo, relembrando que cada pessoa possui um tempo para conseguir superar as dificuldades.

\subsubsection{Quinto encontro - Ansiedade: como lidar?}

A ansiedade foi a temática escolhida para ser abordada no grupo porque no encontro anterior foi trabalhado o bullying e, através disso, a presença de comportamentos e sentimentos ansiosos foram percebidos, verificando-se intensidade quanto a isso. De acordo com o DSM-5 (2014), a ansiedade é a antecipação de ameaça futura, além de estar frequentemente relacionada a tensão muscular e vigilância em preparação para perigo futuro e comportamentos de cautela e esquiva. Então, foi escolhida uma abordagem mais informativa para se trabalhar a respeito do assunto, e os integrantes receberam informações sobre o que fazer quando se sentissem ansiosos, além de informações sobre o que constitui a ansiedade e que ela pode ser superada. Neufeld, Ferreira \& Maltoni (2016), descrevem a técnica de "cheirar a flor e assoprar a vela", na qual se faz uma analogia à inspiração como sentir o cheiro de uma flor, e à expiração como assoprar uma vela. Essa técnica também foi passada aos integrantes do grupo, já que pode se constituir em uma aliada contra alguns momentos ansiosos.

Os participantes leram as informações compartilhadas na tela sobre 0 assunto, parecendo bastante empolgados a respeito de participarem, sentindo-se colaborativos. Ao longo do encontro foi verificada uma mágoa, em geral, com familiares quando estes não se importam com os sentimentos deles, ou ao banalizarem a intensidade do que sentem. O fechamento foi constituído com a síntese do que ficou apreendido a respeito da ansiedade. Ao final do encontro, os participantes também relataram que os demais poderiam contar com eles quando precisassem.

\subsubsection{Sexto encontro - Modelo Cognitivo}


Pensando-se no que havia aparecido em momentos anteriores e levando em consideração o fato de que os encontros estavam chegando ao fim, as coordenadoras apresentaram aos integrantes uma ferramenta que consideraram poder auxiliá-los em situações posteriores. Para isso, o Modelo Cognitivo de Aaron T. Beck, fundador da terapia cognitiva, foi transmitido aos jovens. A seguir, Judith S. Beck auxilia-nos na compreensão dos passos do Modelo Cognitivo:

A forma como as pessoas se sentem emocionalmente e a forma como se comportam estão associadas a como elas interpretam e pensam a respeito da situação. A situação em si não determina diretamente como elas se sentem ou o que fazem; a sua resposta emocional é mediada pela percepção da situação. (BECK; 2014; p. 55)

As coordenadoras produziram um material baseado nos processos do modelo cognitivo, para que os integrantes conseguissem agir com menos impactos negativos diante de situações inesperadas. Sendo assim, foi solicitado lessem o material produzido, o qual trazia os seguintes títulos: Situação - Pensamento - Emoção Comportamento. A cada leitura feita, as coordenadoras revezaram-se na explicação de cada um dos processos, evidenciando que situações despertam um pensamento automático, o qual gera uma emoção equivalente e um comportamento funcional ou não. A ideia principal foi trazer a reflexão para os participantes sobre como eles estariam reagindo frente às situações nas quais eles não teriam controle (incluindo as decorrentes da pandemia do Coronavírus) e, em seguida, que o grupo construísse em conjunto algumas estratégias que todos pudessem exercer.

\subsubsection{Sétimo encontro - Reconhecendo as emoções}

Para esse encontro, trabalhou-se sobre o reconhecimento das emoções e maneiras funcionais de encararem cada uma delas, relembrando que as dinâmicas dos encontros tentavam embasar-se nas demandas percebidas dos encontros anteriores. Para Beck (2014), a forma como as pessoas sentem-se emocionalmente está relacionada a como elas interpretam e pensam uma situação.

A fim de proporcionar uma aproximação com a realidade dos participantes, foi passado o Trailer do Filme Divertidamente (2015) e, a partir disso, os integrantes contribuíram ativamente, contando quais eram suas emoções favoritas mostradas no filme. Nesse sentido, buscou-se dar seguimento ao trabalho no grupo com o mesmo caráter um tanto informativo dos encontros anteriores e, assim, explicou-se sobre 
algumas emoções básicas como medo, raiva, nojo, tristeza e alegria, e ao que elas podem estar relacionadas, de acordo com Beck. Foram passadas imagens na tela para auxiliar na transmissão da dinâmica do dia.

Os participantes também contribuíram ao relatarem algumas das situações nas quais eles já sentiram as emoções trabalhadas no encontro, ainda contando o que costumavam fazer nessas ocasiões. As coordenadoras validaram suas ações e sensações, mas também abordaram algumas propostas de comportamento para quando sentissem alguma emoção específica, como tentar técnicas de respiração nos primeiros segundos em que raiva ou medo aparecem, por exemplo. O fechamento ocorreu com algumas combinações sobre o próximo encontro e retomada de que seria o último, onde foi pedido que fizessem algo artístico que representasse o que as trocas e momentos de aprendizagem ali ocorridos significaram.

\subsubsection{Oitavo e último encontro - 0 encerramento do processo}

Para Afonso (2010), é necessário trabalhar o fim, para que a produtividade do que ocorreu possa ser sentida como positiva pelo grupo e como algo que os participantes podem levar para outras instâncias de seu cotidiano. Assim, seguindo os pressupostos da autora, o último encontro ocorreu com a finalização de algumas elaborações sobre o final do grupo terapêutico e o que ele significou, sendo que esse processo já havia começado no encontro retrasado, quando foi informada a data do último encontro. Foi pedido que os participantes falassem como estavam se sentindo diante do final, e a resposta acordada pelo grupo foi que estavam tristes porque estava acabando, mas felizes por terem feito parte disso.

Em seguida, foi passada uma música que todos ouviram juntos: "É preciso (a próxima parada)", da banda Jota Quest, a qual foi escolhida pelas coordenadoras já que a letra poderia deixar uma mensagem relacionada a um pouco do que foi abordado durante todo o andamento do grupo terapêutico. Os integrantes comentaram que entenderam, através da música, a importância de falarem sobre seus sentimentos, emoções, angústias e conquistas.

$\mathrm{Na}$ sequência, os participantes apresentaram as criações que haviam preparado para o último encontro, conforme pedido anteriormente. Todos criaram artes que explicitavam, sobretudo, o carinho que sentiram pelas coordenadoras. Por 
fim, as coordenadoras apresentaram na tela uma mensagem dizendo que o processo ali ocorrido também seria marcante para elas, e que os integrantes sempre estariam em suas boas memórias. Para finalizar, relacionando com o que foi trabalhado ao longo dos encontros, também foi relatado que alguns anseios perpassaram as coordenadoras em alguns momentos, mas que elas tentaram enfrentá-los com os recursos que dispunham. Cada uma também falou brevemente sobre cada participante ali presente, por fim enfatizando suas contribuições singulares para a ocorrência e as trocas que o grupo terapêutico possibilitou.

\section{CONCLUSÃO}

Diante do objetivo da proposta de intervenção grupal, nas condições descritas e atrelada ao cenário escolar, concluiu-se, com a referida experiência, que essa prática pode proporcionar, de fato, ganhos terapêuticos. Em relação a algumas questões subjetivas intensificadas pela pandemia, para os pré-adolescentes, o caráter vivencial e relacional dos encontros grupais mostrou-se positivo para que tais questões já fossem trabalhadas.

Como já mencionado, desafios foram encontrados, tanto em relação a própria prática, quanto ao encontrar bibliografias sobre o trabalho com grupos online. Por isso, ressalta-se a relevância de uma continuidade em pesquisas sobre a temática, as quais também possam se dar juntamente com a prática, em algumas situações. No presente estudo, recorreu-se a diferentes entendimentos da psicologia, de forma que as ideias não se misturassem mas se complementassem, dada também a complexidade dos atravessamentos da faixa etária dos integrantes do grupo e a tentativa da realização de um trabalho potente no sistema remoto.

O manejo de um grupo, o ambiente online, e a consideração das peculiaridades sobre o período de transição da infância para a adolescência ao estar na prática todas essas individualmente já poderiam ser desafiadoras, e em conjunto por vezes pareceram ainda mais - no entanto, ressalta-se que, sendo as ferramentas que estavam disponíveis no momento, e diante da vontade dos integrantes do grupo, pouco a pouco os obstáculos da referida prática foram sendo suavizados pelos seus 
benefícios. Os jovens demonstraram-se felizes por fazer parte do processo, além de terem sido os protagonistas nas situações propostas.

\section{REFERÊNCIAS}

AFONSO, M. L. M. Oficinas em Dinâmicas de Grupo: um método de intervenção psicossocial. 3. ed. São Paulo: Casa do Psicólogo, 2010.

BECK, J. S. Terapia Cognitivo-Comportamental Teoria e Prática. 2. ed. Porto Alegre: Artmed, 2014.

BERSTEIN, M. Contribuições de Pichon-Rivière à psicoterapia de grupo. In: OSORIO, Luiz Carlos. Grupoterapia hoje. Porto Alegre: Artes Medicas, 1986. DONNAMARIA, Carla Pontes; TERZIS, Antonios. Experimentando o dispositivo terapêutico de grupo via internet: primeiras considerações de manejo e desafios éticos. In: Revista da SPAGESP, vol. 12, n. 2, pp.17-26. Campinas, 2011. DUNKER, C. I. L. A Demanda na Criança e no Adolescente: transformações no estatuto da imagem. In: Sig: Revista de Psicanálise. Vol. 1, n. 2. Porto Alegre: Sigmund Freud Associação Psicanalítica, 2013.

MANUAL DIAGNÓSTICO E ESTATÍSTICO DE TRANSTORNO MENTAIS: DSM-5; [American Psychiatric Association; tradução: Maria Inês Corrêa Nascimento... et al.]; revisão técnica: Aristides Volpato Cordioli... [et al.]. 5. ed. Porto Alegre: Artmed, 2014; Reimp. 2018.

MARTINS, Sueli Terezinha Ferreira. Processo grupal e a questão do poder em Martín-Baró. In: Psicologia \& Sociedade, vol. 15, n. 1.Belo Horizonte, 2003. MONTEIRO, S. S. (Re)inventar educação escolar no Brasil em tempos da covid-19. In: Revista Augustus; v. 25; n. 51; jul./out. 2020.

NEUFELD, C. B.; FERREIRA, I. M. de F.; MALTONI, J. Grupos para crianças e adolescentes em contexto escolar. In: A prática da psicologia na escola: introduzindo a abordagem cognitivo-comportamental. Org: FAVA, D. C. Artesã, 2016.

WEISS, Maria Lucia Lemme. Psicopedagogia clínica: uma visão diagnóstica dos problemas de aprendizagem escolar. 14ª Ed: Lamparina, 2020. 